\title{
Effect of Duration of Surgery on Liver Enzymes After Cholecystectomy: Safety or Duration
}

\author{
Abhishek Sharma ${ }^{\mathrm{a}}$, Rikki Singal ${ }^{\mathrm{a}}$, Amit Mittal ${ }^{\mathrm{b}}$, Amarjit Singh Grover $^{\mathrm{a}}$, \\ Muzzafar Zaman a, c
}

\begin{abstract}
Background: An elevation of serum liver enzymes after laparoscopic cholecystectomy (LC) occurs due to transient decrease in splanchnic blood flow. The changes are attributed to $\mathrm{CO}_{2}$ gas inside the abdominal cavity for a prolonged period as compared to open surgeries.
\end{abstract}

Methods: This study was conducted in the Department of Surgery at M. M. Institute of Medical Sciences and Research, Mullana, Haryana, India. A total number of 300 patients diagnosed as cholelithiasis were included from January 2014 for a period of 2 years. These patients were randomly divided into three groups: LC was done in groups A and B (intraabdominal pressures of 10 and $14 \mathrm{~mm} \mathrm{Hg}$, respectively) and in group C, open cholecystectomy was performed. In all the patients, liver function tests (LFTs) were done pre- and postoperatively and the levels changed in LFTs were noted.

Results: In LC, changes were seen in serum bilirubin, aspartate transaminase (AST) and alanine transaminase (ALT) after $24 \mathrm{~h}$ of surgery. But there was not much difference observed between pre- and post-surgery in LFTs $(\mathrm{P}>0.05)$. In LC, with low pressure (short and long duration), LFTs were changed to less extent than in high pressure (short). In prolonged surgery under high pressure, LFT significantly changed postoperatively $(\mathrm{P}<0.05)$.

Conclusion: Duration of surgery has definitively impact on the liver enzymes but it does not remain for prolonged period. Not only the prolonged time but also pneumoperitoneum pressure affects liver enzymes in laparoscopic surgery especially in high pressure $\mathrm{CO}_{2}$.

Keywords: Laparoscopy; Liver function tests; Open cholecystec-

Manuscript submitted November 16, 2017, accepted December 15, 2017

${ }^{a}$ Department of Surgery, Maharishi Markandeshwer Institute of Medical Sciences and Research, Mullana, Distt-Ambala, Haryana, India

${ }^{b}$ Department of Radiology, Maharishi Markandeshwer Institute of Medical Sciences and Research, Mullana, Ambala, Haryana, India

${ }^{\mathrm{c} C o r r e s p o n d i n g ~ A u t h o r: ~ M u z z a f a r ~ Z a m a n, ~ D e p a r t m e n t ~ o f ~ S u r g e r y, ~ M a h a r i s h i ~}$ Markandeshwer Institute of Medical Sciences and Research, Mullana, DisttAmbala, Haryana, India. Email: muzzafarzaman@yahoo.com

doi: https://doi.org/10.14740/jcs334w tomy; Surgery; Pneumoperitoneum

\section{Introduction}

The introduction of minimal access surgery for gallbladder surgery has revolutionized the treatment of gallstones [1]. Laparoscopic cholecystectomy (LC) has become the gold standard treatment for symptomatic uncomplicated cholelithiasis and replaced the open cholecystectomy (OC). Because of less postoperative pain, bleeding, shorter hospital stay and better cosmesis, minimal invasive surgery has become the method of choice for the uncomplicated gall bladder stones, hernia repair and appendectomies [2]. To carry out the procedure, various sizes and numbers of ports are used and with time, the number of ports has decreased from four to even single. Two ports can be used as an alternative to the three-port or four-port laparoscopic procedure in case of acute appendicitis with favorable outcomes [3]. Creation of pneumoperitoneum by insufflation with carbon dioxide increases minute ventilation by as much as $60 \%$ and activates the sympathetic nervous system leading to an increase in BP, heart rate, myocardial contractility and arrythmias apart from changes in splanchnic blood flow [4]. A study found that splanchnic ischemia occurs by creation of the pneumoperitoneum of $12 \mathrm{~mm} \mathrm{Hg}$ with significantly decreased hepatic and gastric microcirculation during LC [5].

It is evident that changes in liver function test (LFT) after LC occur due to gas present in abdominal cavity, while no change has been demonstrated in OC as seen in our present study. While changes due to prolonged pneumoperitoneum have not been studied, neither much literature is present worldwide. A study in 2011 compared the laparoscopic gastrectomy (LG) and open gastrectomy (OG), and found that mean AST levels on postoperative days 1 and 3, and mean ALT and total bilirubin levels on days 1,3 , and 7 , were significantly raised in the LG group $(\mathrm{P}<0.001)$ [6]. One of the important hemodynamic changes is the transient reduction in hepatic blood flow caused by a pneumoperitoneum. The pressure of a created pneumoperitoneum and its duration were shown to influence the degree of hepatic ischemia by causing elevations in liver enzymes [7]. In the present study, patients undergone $\mathrm{LC}$ or OC and we observed the changes in liver enzymes in relation to timing of surgery along with intraperitoneal pressure kept for surgery (10 or $14 \mathrm{~mm} \mathrm{Hg}$ ). Changes due to prolonged pneumoperitoneum are a 
Table 1. Gender Distribution of Patients

\begin{tabular}{llllll}
\hline Group A $(\mathbf{1 0 ~} \mathbf{~ m m ~ H g})$ & $\mathbf{( N = 1 0 0 )}$ & \multicolumn{2}{l}{ Group B $(\mathbf{1 4} \mathbf{~ m m ~ H g})(\mathbf{N}=\mathbf{1 0 0})$} & \multicolumn{3}{l}{ Group C $(\mathbf{O C})(\mathbf{N}=\mathbf{1 0 0})$} \\
\hline Males & Females & Males & Females & Males & Females \\
$15(15 \%)$ & $75(75 \%)$ & $22(22 \%)$ & $78(78 \%)$ & $20(20 \%)$ & $80(80 \%)$ \\
\hline
\end{tabular}

well known factor but in relation to duration of surgery have not been studied and neither much literature is present worldwide.

\section{Materials and Methods}

The prospective study was done in the Department of Surgery since January 2014 for a period of 2 years at M. M. Institute of Medical Sciences and Research, Mullana, Haryana, India. The protocol for the research project has been approved by a suitably body constituted Ethics Committee of the institution within which the work was undertaken. A total number of 300 patients were included in the study. It included both genders with acute or chronic cholecystitis with cholelithiasis admitted for laparoscopic or open surgery. Patients with acute cholecystitis presented within $48 \mathrm{~h}$ of symptoms without any co-morbidity. The patients were willing to be part of the study group. The patients with pre-operative deranged liver enzymes, contraindication to laparoscopic surgery, chronic liver diseases, common bile duct (CBD) pathology or injury, pregnancy or any abnormality in coagulation profile were excluded from the study. Patients were randomly divided into three groups: in groups A and B, LC was performed and in group C, OC was performed. In group $\mathrm{A}$, the abdominal $\mathrm{CO}_{2}$ pressure was maintained as $10 \mathrm{~mm} \mathrm{Hg}$, in group B, pressure kept $14 \mathrm{~mm} \mathrm{Hg}$ and group $\mathrm{C}$ was without pressure as it was OC.

A written informed consent was taken pre-operatively for all the groups. All patients underwent a standard clinical and laboratory evaluation that included briefly information, and ultrasound of the abdomen. Pre-operative investigations included renal functions and LFTs (ALT, AST, alkaline phosphatase, and gamma glutamyl transferase, bilirubin direct and total). The LFTs were further done 24 - $48 \mathrm{~h}$ later and in some patients LFT was repeated to monitor liver function. Any adverse events were noted in all the patients. Finally the duration of hospital stay was noted.

\section{Operative techniques}

In group $\mathrm{A}$, pneumoperitoneum was created and maintained by intraperitoneal $\mathrm{CO}_{2}$ insufflation up to $10 \mathrm{~mm} \mathrm{Hg}$. In group $\mathrm{B}$, pneumoperitoneum was maintained up to $14 \mathrm{~mm} \mathrm{Hg}$. In both the groups, patient's head was elevated and right-sided tilted upwards towards the left side. Four ports were made: 10 $\mathrm{mm}$ port infraumblical site, epigastrium region and two $5 \mathrm{~mm}$ ports; right lateral and in subcostal region two fingers below midlaviculer area. Structures are identified in Calot's triangle and clip was applied to the cystic duct and cystic artery after proper dissection of callots triangle and identification of structures to avoid injury to CBD. Gallbladder was removed from the liver bed with the help of diathermy.

Drain was kept in all the cases and removed generally on second postoperative day when amount was less than $20 \mathrm{~mL}$. If bile leakage was present, then antibiotics were used for 5 days. In group $\mathrm{C}, \mathrm{OC}$ was done under general anesthesia. Kochers right subcostal incision was made and abdomen was opened in layers and findings were confirmed. In most of the patients, cholecystectomy was done using duct first method. Hemostasis was achieved and a tube drain was kept in subhepatic space. In all the groups, analgesics were given in the form of injection voveran (diclofenac) and if required tramadol was also given to all the patients for 2 days and then patients were put on oral analgesic drugs for 10 days. Sutures were removed from 8 to 10 days.

\section{Results}

Patients were divided into three groups: A, B and C. Groups $\mathrm{A}$ and $\mathrm{B}$ underwent $\mathrm{LC}$ with intraabdominal pressure of 10 and $14 \mathrm{~mm} \mathrm{Hg}$, respectively, while group $\mathrm{C}$ patients underwent OC. All the cases were done under general anesthesia. Most of the patients were females in all the groups. In group A, there were 15 males and 75 females, in group B, there were 22 males and 78 females and in group $\mathrm{C}$, there were 20 males and 80 females (Table 1). In OC, the time taken to complete the procedure was 41 - 70 min except for few patients of acute cholecystitis and one patient of gallbladder empyema who took more than $1 \mathrm{~h}$ to complete the surgery. In LC, maximum time was about 20 - $50 \mathrm{~min}$, and few patients took $90 \mathrm{~min}$ also (Table 2).

Table 2. Duration of Surgery in Three Groups Undergoing Laparoscopic Cholecystectomy Done in a Single Unit

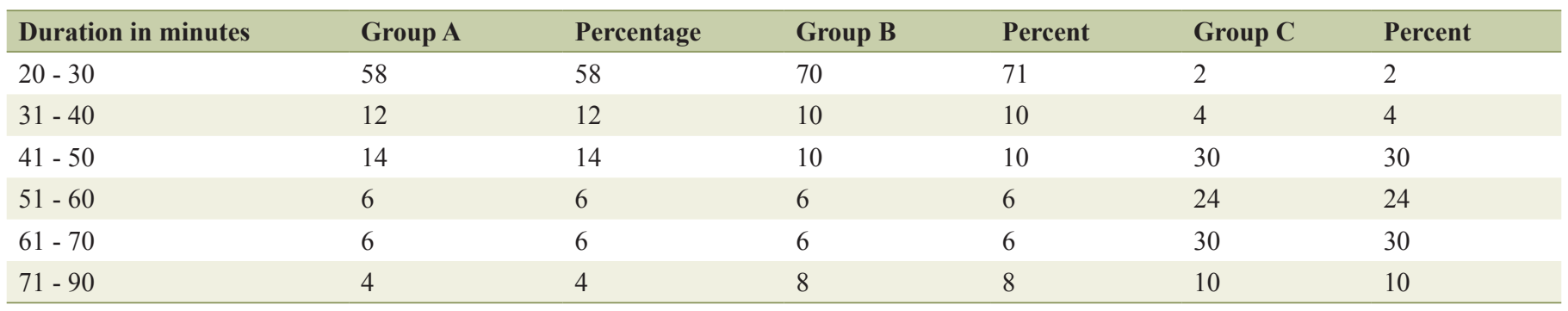


Table 3. Effects on LFT in Low and High Pressure Group With Duration Less Than One Hour

\begin{tabular}{lllllll} 
Parameters & $\begin{array}{l}\text { Group A before } \\
\text { surgery }\end{array}$ & $\begin{array}{l}\text { Group A after } \\
\text { surgery }\end{array}$ & $\begin{array}{l}\text { Group B before } \\
\text { surgery }\end{array}$ & $\begin{array}{l}\text { Group B after } \\
\text { surgery }\end{array}$ & $\begin{array}{l}\text { Group C (OC) before } \\
\text { surgery }\end{array}$ & $\begin{array}{l}\text { Group C (OC) after } \\
\text { surgery }\end{array}$ \\
\hline Bilirubin & $0.6162 \pm 0.20$ & $0.60 \pm 0.22$ & $1.8 \pm 0.22$ & $1.9 \pm 0.01$ & $0.51 \pm 0.1$ & $0.54 \pm 0.2$ \\
AST & $68.15 \pm 10.50$ & $61.58 \pm 11.2$ & $66.4 \pm 11.3$ & $69 \pm 0.35$ & $26.0 \pm 4.7$ & $28.2 \pm 4.8$ \\
ALT & $98.50 \pm 13.78$ & $99.65 \pm 15.79$ & $60.8 \pm 10.54$ & $72 \pm 0.57$ & $24.5 \pm 4.7$ & $27.7 \pm 4.9$ \\
ALP & $128.79 \pm 34.66$ & $132 \pm 20.23$ & $98.40 \pm 36$ & $88.39 \pm 33.35$ & $59.8 \pm 13.6$ & $61 \pm 12.04$ \\
\hline
\end{tabular}

Table 4. Effects on LFTS in Low and High Pressure Group With Duration More Than One Hour

\begin{tabular}{lllllll}
\hline Parameters & $\begin{array}{l}\text { Group A before } \\
\text { surgery }\end{array}$ & $\begin{array}{l}\text { Group A after } \\
\text { surgery }\end{array}$ & $\begin{array}{l}\text { Group B before } \\
\text { surgery }\end{array}$ & $\begin{array}{l}\text { Group B after } \\
\text { surgery }\end{array}$ & $\begin{array}{l}\text { Group C (OC) before } \\
\text { surgery }\end{array}$ & $\begin{array}{l}\text { Group C (OC) after } \\
\text { surgery }\end{array}$ \\
\hline Bilirubin & $0.57 \pm 0.35$ & $0.99 \pm 1.46$ & $0.383 \pm 0.34$ & $0.623 \pm 0.26$ & $0.61 \pm 0.1$ & $0.61 \pm 0.2$ \\
AST & $68.15 \pm 24$ & $78.45 \pm 27$ & $38.51 \pm 16.23$ & $48.13 \pm 0.56$ & $29.0 \pm 4.7$ & $26.2 \pm 4.8$ \\
ALT & $98.50 \pm 24.57$ & $124 \pm 0.57$ & $49.33 \pm 0.36$ & $65.96 \pm 78$ & $29.5 \pm 4.7$ & $32.7 \pm 4.9$ \\
ALP & $110.68 \pm 18.89$ & $128.79 \pm 24.7$ & $98.40 \pm 15$ & $110 \pm 2.8$ & $59.8 \pm 13.6$ & $61 \pm 12.04$ \\
\hline
\end{tabular}

The results were obtained after applying proper statistical methods and tests to the values obtained in the study. Changes in LFTs were noted in all the three groups in relation to pressure and duration of surgery. It was found that with duration of surgery less than $1 \mathrm{~h}$ in 10 and $14 \mathrm{~mm} \mathrm{Hg}$ pressured, less alterations were observed in LFTs $(\mathrm{P}>0.05)$. There was a change in LFT but was very minimal as the duration of procedure was less than $1 \mathrm{~h}$ (Table 3 ). In group A, pre-operatively the mean bilirubin was $0.6162 \pm 0.20$ while postoperative level was 0.60 \pm 0.22 , pre-operative mean of AST was $68.15 \pm 10.50$ while postoperatively it was $61.58 \pm 11.20$, pre-operative ALT was $98.50 \pm 13.78$ while postoperative value was $99.65 \pm 15.79$ and pre-operative ALP value was $128.79 \pm 34.66$ and postoperative was $132 \pm 29.30$. The $\mathrm{P}$ value was more than 0.05 , so the results were non-significant. In group $\mathrm{B}$, pre-operative serum bilirubin was $1.8 \pm 0.22$ while postoperatively it was 1.9 \pm 0.01 , pre-operative level of AST was $66.40 \pm 11.30$ while postoperative was $69 \pm 0.35$, pre-operative value of ALT was $60.80 \pm 10.54$ while postoperative was $72.0 \pm 0.57$, pre-operative value of ALP was $98.40 \pm 36.22$ while postoperative value was $88.39 \pm 33.35$; the $P$ value was non-significant as obtained from the results (Table 3 ).

In patients, where surgery took more than $1 \mathrm{~h}$ in group A, the pre-operative level of bilirubin was $0.57 \pm 0.35$ while postoperatively it was $0.99 \pm 1.46$, pre-operative value of AST was $68.15 \pm 24$ while postoperative value was $78.45 \pm 27$, preoperative value of ALT was $98.50 \pm 24.57$ while postoperative was $124 \pm 0.57$, pre-operative value of ALP was 110.68 \pm 18.89 while postoperative was $128.79 \pm 24.70$. In group $\mathrm{B}$, with longer duration of surgery, the pre-operative level of bilirubin was $0.383 \pm 0.34$, postoperative was $0.623 \pm 0.26$, pre-operative level of AST was $38.51 \pm 16.23$ and postoperative value was $48.13 \pm 0.56$, pre-operative value of ALT was $98.50 \pm 24.57$, pre-operative value of ALP was $98.40 \pm 15$ and postoperative level was $110 \pm 2.8$. The $\mathrm{P}$ value obtained from these observations was less than 0.05 , hence significant (Table 4). So in case of patients who took more than $1 \mathrm{~h}$ for the procedure in low pressure and more in high pressure group also, more changes in LFTs were observed postoperatively ( $\mathrm{P}$ $<0.05)$.

In group $\mathrm{C}$, there were no significant changes seen in LFTs after surgery (Table 5). The P value obtained was more than 0.05 (non-significant), hence the differences in LFTs are less. So from the above observations, we concluded that it is the duration during which $\mathrm{CO}_{2}$ is retained inside the abdominal cavity that affects LFTs along with high abdominal pressures kept for LC.

\section{Discussion}

Minimal access surgery is widely practiced and offers several benefits over open classical surgery. However, there are various contraindications to the procedure also especially compromised liver functions preoperatively. Patients with cirrhosis and portal hypertension are at risk for two reasons: low pe-

Table 5. Changes in LFT in Patients Who Underwent Open Cholecystectomy After 48 h of Procedure

\begin{tabular}{llll}
\hline Parameter & $\mathbf{2 4} \mathbf{h}$ before OC (pre-operative mean) & $\mathbf{4 8} \mathbf{h}$ after $\mathbf{O C}$ (postoperative mean) & P value \\
\hline Serum bilirubin & $0.51 \pm 0.1$ & $0.51 \pm 0.2$ & NS \\
AST (IU/L) & $26.0 \pm 4.7$ & $26.2 \pm 4.8$ & NS \\
ALT (IU/L) & $24.5 \pm 4.7$ & $24.7 \pm 4.9$ & NS \\
ALP (IU/L) & $59.8 \pm 13.6$ & $61 \pm 12.04$ & NS \\
\hline
\end{tabular}


ripheral resistance and the risk of bleeding that is difficult to control during the procedure so in these patients LC should not be attempted. The adverse physical effects of intraabdominal hypertension were reviewed in detail recently [8]. Key hole surgery has become the method of preference for surgeons as well as patients for the treatment of uncomplicated gallbladder stones, hernia repair and appendectomies. Pneumoperitoneum has gotten various effects on human physiology including some alterations in liver enzymes as evidenced in literature worldwide [9]. Another study found statistically significant increased levels of hepatic transaminases during the first $48 \mathrm{~h}$ of surgery LC which was also seen in our study [10].

With the intraabdominal pressure of $12 \mathrm{~mm} \mathrm{Hg}$, the changes in LFTs were observed during LC by Neri et al [11]. The levels of AST and ALT increased significantly during 24 - $48 \mathrm{~h}$ after LC $(\mathrm{P}<0.0001)$ which was also observed in our study $(\mathrm{P}<0.05)$. A study done on LC showed no significant difference in serum bilirubin, AST, ALT and ALP after 24 and $72 \mathrm{~h}$ of surgery [12]. In the present study, significant difference in LFT was noted where time required for surgery was more than $1 \mathrm{~h}$ in LC. Patient factors like BMI, male gender, higher ASA, and abnormal pre-operative LFT are the main factors that determine the difficulty levels in lap chole and can cause prolonged duration of surgery as studied by Lowndes et al [13]. A prerequisite for successful results of cholecystectomy is the pre-operative exclusion of associated silent choledocholithiasis because persistence of CBD calculi, negative CBD exploration or any other procedure like endoscopic retrograde cholangiopancreography (ERCP), is related to an increase in morbidity and expenses $[14,15]$. We observed that duration of surgery along with high pressure abdominal insuffulation gas may affect on liver enzymes in LC but no effect was seen in OC. It is also evidenced in literature that no changes are seen in LFTs after OC. With increase in abdominal pressure along with more duration of surgery, the changes in LFTs are more as compared to less duration of surgery under low or high pressure pneumoperitoneum. In present study, we observed if duration of surgery is less in 14 or $10 \mathrm{~mm} \mathrm{Hg}$, then liver enzymes changes were seen but less significant. We observed that surgeons should not be biased by duration or changes seen in liver enzyme as patient safety is necessary because enzyme changes are transitory and by time it comes to normal.

Prolonged duration of surgery and high intraabdominal pressure in laparoscopy change the liver enzymes postoperatively but it is transitory. The changes in liver enzyme were less, if duration of surgery is less up to $30-60 \mathrm{~min}$, even in high pressures. No changes were encountered in $\mathrm{OC}$ in spite of long duration of surgery. Duration of surgery and intraabdominal pressure are not the matter but it is the safety of the patient which is of prime importance.

\section{Conclusion}

Magnitude of pressure of pneumoperitoneum in case of LC or OC has not gotten any adverse effects on LFTs postoperatively. It is the time up to which $\mathrm{CO}_{2}$ is retained inside the abdominal cavity that has gotten adverse effects on liver function enzymes which is transient.

\section{Conflict of Interest}

None.

\section{Funding}

None.

\section{Abbreviations}

CBD: common bile duct; ERCP: endoscopic retrograde cholangiopancreaticography; EUS: endoscopic ultrasonography; USG: ultrasonography; LFT: liver function test; ALT: alanine transaminase; AST: aspartate transaminase; ALP: alkaline phosphatase; LC: laparoscopic cholecystectomy; OC: open cholecystectomy; NS: non-significant

\section{References}

1. Singal R, Goyal P, Zaman M, Mishra RK. Comparison of three-port vs four-port laparoscopic cholecystectomy in a medical college in the periphery. World J Lap Surg. 2017;10(1):1-5.

2. Zaman M, Singal S, Singal R, Shah A, Sandhu KS, Singh $\mathrm{B}$, et al. Comparison of open and closed entry techniques for creation of pneumoperitoneum in laparoscopic surgery in terms of time consumption, entryrelated complications and failure of technique. World $\mathrm{J}$ of Laparoscopic Surg. 2015;8:69-71.

3. Gupta R, Singal R, Sharda VK, Singh B, Ahluwalia JS, Bhatia G, et al. Two port laparoscopic assisted appendicectomy versus three port laparoscopic appendicectomy: A prospective study of 50 cases. Trop J Med Res. 2015;18:14-19.

4. Bhoorasingh P, McCartney T, Simpson LK. Jaundice post laparoscopic cholecystectomy. West Indian Med J. 2010;59(1):88-91.

5. Gupta R, Kaman L, Dahiya D, Gupta N, and Singh R. Effect of varying intraperitoneal pressure on liver function tests during laparoscopic cholecystectomy. Journal of Laparoendoscopic \& Advanced Surgical Techniques. 2013;23: 339-342.

6. Kinjo Y, Okabe H, Obama K, Tsunoda S, Tanaka E, Sakai Y. Elevation of liver function tests after laparoscopic gastrectomy using a Nathanson liver retractor. World J Surg. 2011;35(12):2730-2738.

7. Rao PR, Kongara S, Snigdha Y, Kalyan KASSN. Study of alterations in liver function tests following laparoscopic surgery. IOSR Journal of Dental and Medical Sciences. 2017;16:48-54.

8. Gurusamy KS, Samraj K, Davidson BR. Low pressure versus standard pressure pneumoperitoneum in laparoscopic cholecystectomy. Cochrane Database Syst Rev. 2009;(2):CD006930.

9. Singal R, Zaman M, Mittal A, Singal S, Sandhu K. no 
need of fascia closure to reduce trocar site hernia rate in laparoscopic surgery: a prospective study of 200 nonobese patients. Gastroenterology Res. 2016;9(4-5):70-73.

10. Tan M, Xu FF, Peng JS, Li DM, Chen LH, Lv BJ, Zhao $\mathrm{ZX}$, et al. Changes in the level of serum liver enzymes after laparoscopic surgery. World J Gastroenterol. 2003;9(2):364-367.

11. Neri V, Ambrosi A, Fersini A, Tartaglia N, Cianci P, Lapolla F, Forlano I. Laparoscopic cholecystectomy: evaluation of liver function tests. Ann Ital Chir. 2014;85(5):431-437.

12. Singal R, Singal RP, Sandhu K, Singh B, Bhatia G, Khatri A, Sharma BP. Evaluation and comparison of postoperative levels of serum bilirubin, serum transaminases and alkaline phosphatase in laparoscopic cholecystectomy versus open cholecystectomy. J Gastrointest Oncol. 2015;6(5):479-486.

13. Lowndes B, Thiels CA, Habermann EB, Bingener J, Hallbeck S, Yu D. Impact of patient factors on operative duration during laparoscopic cholecystectomy: evaluation from the National Surgical Quality Improvement Program database. Am J Surg. 2016;212(2):289-296.

14. Robinson TN, Biffl WL, Moore EE, Heimbach JK, Calkins CM, Burch J. Routine preoperative laboratory analyses are unnecessary before elective laparoscopic cholecystectomy. Surg Endosc. 2003;17(3):438-441.

15. Nugent N, Doyle M, Mealy K. Low incidence of retained common bile duct stones using a selective policy of biliary imaging. Surgeons. 2005;3:352-356. 